\title{
Comparative examination of various PCR-based methods for DNMT3A and IDH1/2 mutations identification in acute myeloid leukemia
}

\author{
Rimma Berenstein ${ }^{1 *}$, Igor Wolfgang Blau ${ }^{1}$, Asiye Kar $^{2}$, Ruhiye Cay ${ }^{2}$, Annette Sindram³ ${ }^{3}$ Claudia Seide $^{3}$ and Olga Blau ${ }^{1,3}$
}

\begin{abstract}
Background: Mutations in epigenetic modifiers were reported in patients with acute myeloid leukaemia (AML) including mutations in DNA methyltransferase 3A gene (DNMT3A) in 20\%-30\% patients and mutations in isocitrate dehydrogenase $1 / 2$ gene (IDH1/2) in 5\%-15\% patients. Novel studies have shown that mutations in DNMT3A and IDH1/2 influence prognosis, indicating an increasing need to detect these mutations during routine laboratory analysis. DNA sequencing for the identification of these mutations is time-consuming and cost-intensive. This study aimed to establish rapid screening tests to identify mutations in DNMT3A and IDHI/2 that could be applied in routine laboratory procedures and that could influence initial patient management.
\end{abstract}

Methods: In this study we developed an endonuclease restriction method to identify the most common DNMT3A mutation (R882H) and an amplification-refractory mutation system (ARMS) to analyse IDH2 R140Q mutations. Furthermore, we compared these methods with HRM analysis and evaluated the latter for the detection of IDH1 mutations.

Results: Of 230 samples from patients with AML 30 (13\%) samples had DNMT3A mutations, 16 (7\%) samples had IDH2 R140Q mutations and 36 (16\%) samples had IDH1 mutations. Sensitivity assays performed using serial dilutions of mutated DNA showed that ARMS analysis had a sensitivity of 4.5\%, endonuclease restriction had a sensitivity of $0.05 \%$ and HRM analysis had a sensitivity of 5.9\%-7.8\% for detecting different mutations. HRM analysis was the best screening method to determine the heterogeneity of IDH1 mutations. Furthermore, for the identification of mutations in IDH2 and DNMT3A, endonuclease restriction and ARMS methods showed a perfect concordance (100\%) with Sanger sequencing while HRM analysis showed a near-perfect concordance (approximately 98\%).

Conclusion: Our study suggested that all the developed methods were rapid, specific and easy to use and interpret. HRM analysis is the most timesaving and cost-efficient method to rapidly screen all the 3 genes at diagnosis in samples obtained from patients with AML. Endonuclease restriction and ARMS assays can be used separately or in combination with HRM analysis to obtain more reliable results. We propose that early screening of mutations in patients with AML having normal karyotype could facilitate risk stratification and improve treatment options.

Keywords: AML, DNMT3A, IDH1/2 mutations, DNA sequencing, HRM analysis, ARMS PCR, Endonuclease restriction

\section{Background}

Acute myeloid leukaemia (AML) is a clonal disorder characterised by the accumulation of myeloid cells and impairment of normal haematopoiesis [1]. The recent large-scale sequencing of AML genomes is now providing opportunities for patient stratification and personalised approaches to treatments that are based on an individual's mutation

\footnotetext{
* Correspondence: rimma.berenstein@charite.de

'Department of Hematology, Oncology and Tumourimmunology, Charité Universitätsmedizin Berlin, Hindenburgdamm 30, 12200 Berlin, Germany
} Full list of author information is available at the end of the article profiles [1-3]. A few recurring gene mutations and overexpressed genes having prognostic relevance in AML have been identified and incorporated in the current prognostication models.

Recently, a new class of mutations affecting genes for DNA methylation and post-translational histone modification was identified in AML. These mutations frequently occur in the DNA nucleotide methyltransferase $3 \mathrm{~A}$ gene (DNMT3A) [4-8] and isocitrate dehydrogenase $1 / 2$ gene (IDH1/2) (isocitrat dehydrogenase 1/2) [9-13]. DNMT3A 
belongs to the mammalian methyltransferase gene family, which also includes DNTM1, DNMT3B and DNMT3L. Methyltransferases modify methylation patterns by enzymatically adding a methyl group to cytosine residues in CpG islands and are involved in tissue-specific gene expression $[4,14]$. Studies in different AML cohorts have reported the incidence of DNMT3A mutations in up to $22 \%$ de novo AML and $36 \%$ cytogenetically normal AML samples $[5,6]$. Nonsense, frameshift and missense mutations commonly occur in DNMT3A; however a point mutation at position R882 is the most frequently (40\%-60\%) observed mutation [7]. In vitro studies suggest that mutations at this position disturb the formation of heterodimers with DNMT3L, thereby preventing the catalytic activity of DNMT3A. Different studies have shown a negative impact of DNMT3A mutation on outcomes in patients with AML [3,15-19]. Prognostic effect is known to depend on certain biological factors as well as a combination of cytogenetics and other mutations such as those in FLT3 and NPM1 [3,6,8].

Somatic mutations in $I D H 1 / 2$ occur in $5-30 \%$ patients with AML and are commonly associated with nucleophosmin 1 (NPM1) mutations $[9,10]$. Both the genes play a critical role in the citric acid cycle $I D H 1$ in the cytoplasm and peroxisome and $I D H 2$ in the mitochondria. Both $I D H 1$ and $I D H 2$ promote the conversion of isocitrate to $\alpha$ ketoglutarate $(\alpha-K G)$ that is associated with the reduction of nicotinamide adenine dinucleotide phosphate (NADP ${ }^{+}$) to NADPH $[8,11,20]$. Mutations in IDH1 and $I D H 2$ are heterozygous and occur in highly conserved arginine residues (IDH1 R132 and IDH2 R140/R172). Mutations at IDH2 R140 always result in the conversion of arginine to glutamine, whereas substitutions at IDH1 R132 and IDH2 R172 result in a wide range of amino acid replacements [12]. All point mutations in $I D H 1 / 2$ lead to a gain of function, enabling the conversion of $\alpha-K G$ to 2hydroxyglutarate (2-HG) and oxidation of $\mathrm{NADPH}$ to $\mathrm{NADP}^{+}$. Furthermore, an increase in 2-HG-levels leads to the functional impairment of $\alpha$-KG-dependent enzymes through competitive inhibition [13].

In contrast to the impact of DNMT3A mutations, the impact of $I D H 1 / 2$ mutations on prognosis is not completely understood. It appears that prognosis may depend on specific patient populations and a combination with NPM1 mutations [21-23].

The increasing evidence of high incidence particularly in cytogenetically normal AML and prognostic pertinence of DNMT3A and IDH1/2 mutations support the need to identify these mutations in routine diagnostic screening. Importantly, the presence of $D N M T 3 A$ and $I D H 1 / 2$ mutations may confer sensitivity to novel therapeutic approaches, including demethylating agents $[24,25]$.

The current available methods like direct sequencing are informative but time consuming and cost intensive. In this study, we validated the polymerase chain reaction
(PCR)-based high resolution melt (HRM) assay for screening DNMT3A, IDH1 and IDH2 mutations in samples obtained from patients with AML at diagnosis and developed 2 rapid methods for detecting more common mutations, DNMT3A R882H and IDH2 R140Q. We evaluated the utility of endonuclease restriction-based detection method to identify mutations in DNMT3A and designed an amplification-refractory mutation system (ARMS) to detect mutations in $I D H 2$. In addition we compared both the systems with the HRM assay for all the studied mutations.

\section{Methods \\ Patient characteristics}

Bone marrow (BM) samples from 230 patients with newly diagnosed AML were included in the study. All patients were treated at the University Clinic Charité, Campus Benjamin Franklin, from May 2000 to July 2013. Patient's characteristics are summarised in the Additional file 1: Table S1. The male/female ratio of the study population was $116 / 114$, and the median age was 57 years (range, 1694 years). Diagnoses were established according to the WHO criteria [26]. Written informed consent was obtained from all patients in accordance with the Declaration of Helsinki and the ethical guidelines of the Charite University School of Medicine, which approved this study.

\section{DNA extraction}

Mononuclear cells from BM aspirates were isolated using Ficoll density gradient centrifugation as described [27]. DNA was extracted using Allprep DNA/RNA mini kit (Qiagen) as per the manufacturer's instructions.

\section{ARMS analysis of IDH2-R140Q mutations}

All primers were designed using Primer 3 Software (Additional file 2: Table S2). ARMS analysis was performed using 2 control primers flanking exon 23 and 2 allele-specific primers IDH2-RI and IDH2-FI that are complementary to the wild-type (wt) and mutated alleles, respectively. To enhance specificity, both the primers had an additional medium mismatch at the preliminary base. The PCR mixture and reaction conditions are specified in the Additional file 3: PCR reaction mixtures and conditions. The generated PCR products were analysed on a $1.5 \%$ agarose gel.

\section{Endonuclease restriction analysis of DNMT3A-R882H mutations}

PCR amplification for endonuclease restriction analysis was conducted using primers DNMT3A-ResF/R (Additional file 2: Table S2). PCR reaction mixture was prepared as that described for ARMS assay. The reaction conditions are specified in the Additional file 3. In all, $10 \mu \mathrm{l}$ of the PCR product was directly applied for endonuclease 
treatment with $1 \mu \mathrm{l}$ Fnu4HI and $5 \mu \mathrm{l}$ of CutSmart Buffer (New England Biolabs). After incubation at $37^{\circ} \mathrm{C}$ for 15 min products were analysed on a $1.5 \%$ agarose gel containing $10 \%$ ethidium bromide (voltage $150 \mathrm{~V}$ ).

\section{HRM assay}

The reaction mixture and HRM conditions are specified in the Additional file 3. The analysis was performed in a Rotor Gene 6000 Real-Time PCR Cycler (Qiagen). Samples, including a control sample for each mutation and wt allele, were analysed in duplicates. For DNMT3A and $I D H 2$, the wt allele was used for normalisation, while for IDH1 R132C mutation control was used as the baseline. Normalisation regions for the optimal detection of $D N M T 3 A$ were $82^{\circ} \mathrm{C}-83^{\circ} \mathrm{C}$ (leading range) and $87^{\circ} \mathrm{C}-88^{\circ} \mathrm{C}$ (trailing range), for the optimal detection of $I D H 1$ were $73^{\circ} \mathrm{C}-74^{\circ} \mathrm{C}$ (leading range) and $82^{\circ} \mathrm{C}-83^{\circ} \mathrm{C}$ (trailing range) and for the optimal detection of $I D H 2$ were $77^{\circ} \mathrm{C}-78^{\circ} \mathrm{C}$ (leading range) and $87^{\circ} \mathrm{C}-88^{\circ} \mathrm{C}$ (trailing range). Confidence threshold was set to $70 \%$ for all the genes.

\section{DNA sequencing}

All the primers used for sequencing are listed in the Additional file 2: Table S2. All PCR reaction conditions are specified in the Additional file 3. The obtained products were purified using the PCR Purification Kit (Qiagen), as described in the manual. Sequencing reaction was performed using Big Dye Terminator v3.1 Cycle Sequencing Kit (Applied Biosystems). The sequencing products were purified using DyeEx 2.0 Spin Kit (Qiagen) according to the manufacturer's instructions. The purified products were diluted with $18 \mu \mathrm{l} \mathrm{HiDi-Formamid} \mathrm{(Applied} \mathrm{Biosystems),}$ incubated at $95^{\circ} \mathrm{C}$ for $3 \mathrm{~min}$ and chilled on ice for $3 \mathrm{~min}$. Sequencing was performed using ABI310 Genetic Analyser (Applied Biosystems), and data were collected using ABI Prism 310 Data Collection Software.

\section{Results and discussion}

All the positive and negative controls used in this study were selected by Sanger sequencing of patients' samples. The results obtained using endonuclease restriction, ARMS and HRM were verified with those obtained using Sanger sequencing to determine the specificity of the assays. Sensitivity was measured as the minimal percentage of mutated allele in a sample detected by the assay. The initial portion of mutation was determined using Sanger sequencing.

\section{DNMT3A mutation analysis}

Endonuclease restriction analysis identified DNMT3A R882H G>A mutations in 28 out of 230 patients with AML (12.2\%) and HRM analysis identified 2 additional R882X G>C mutations (0.9\%), which are consistent with the frequency published by Lin et al. [28]. The age of the patients ranged from 24 to 87 years (median, 58 years). Among these patients, 53\% had a normal karyotype. None of the patients in the prognostic favourable group had DNMT3A mutations. Of 30 patients, 16 had FLT3 mutations.

Figure 1 provides a representative result of restriction analysis with 5 positive and 2 negative samples. Point mutation at R82H (GCCGC to GCCAC) led to the loss of
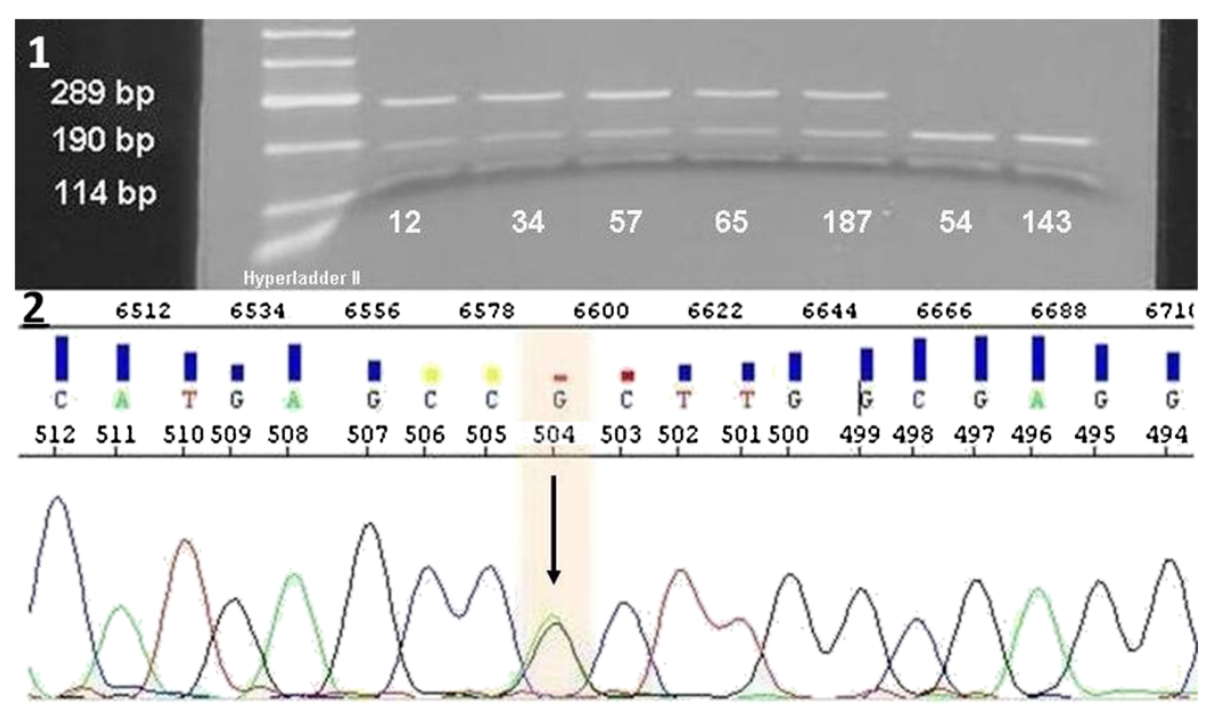

Figure 1 Restriction analysis of DNMT3A R882H mutations. 1) Agarose gel analysis of restricted products of 5 positive $(12,34,57,65,187)$ and 2 negative $(54,143)$ patients. Wt samples showed 2 bands at $190 \mathrm{bp}$ and $114 \mathrm{bp}$. Positive samples showed 3 bands at $289 \mathrm{bp}, 190 \mathrm{bp}$, 114 bp because of the loss of a restriction site of Fnu4HI caused by the mutation. Hyperladder II (Bioline) was used as the marker. 2) Representative sequence analysis of patient 187 showing heterozygote mutation CGC to CAC. 

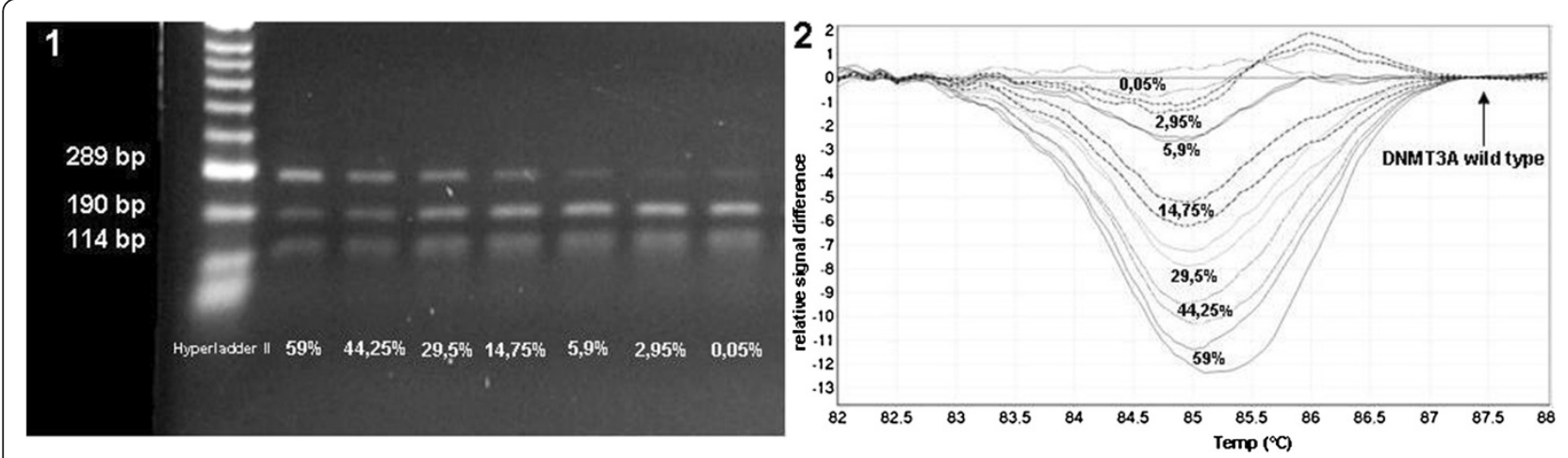

Figure 2 Sensitivity analysis of DNMT3A R882H detection. 1) Endonuclease restriction analysis of serial dilutions of DNMT3A R882H; Undiluted mutation ratio was $59 \%$ (estimated by sequencing). Mutated allele wa detected up to a degree of $0.05 \%$. 2) Difference plot for HRM analysis of serial dilutions of DNMT3A R882H: Correct estimation was possible up to a mutation ratio of 5.9\%; lower mutation ratios were identified false-negative. Normalisation was performed to the wt allele.

one recognition site of Fnu4HI, thus creating a larger 289 bp fragment. Because of heterozygosity, the $190 \mathrm{bp} w \mathrm{wt}$ fragment and the smaller 114 bp fragment are present in every sample. Sensitivity of the assay was analysed using serial dilutions of wt and DNMT3A R882H-mutated DNA (initial mutation ratio in Sanger sequencing was 59\%, Figure 2.1). The fragment containing the mutation was explicitly apparent with a mutational content of $0.05 \%$, indicating a very high sensitivity of the assay. In addition mutations in exon 23 of DNMT3A were detected using HRM analysis. Results of HRM analysis were plotted as a difference in the fluorescence of the tested sample versus that of a wt control (normalisation line), referred to as a temperature-shifted difference plot (Figure 3.1). Discrepancies between mutated and wt samples could also be observed in the melting plot profiles. Sample containing $\mathrm{R} 882 \mathrm{H}$ mutation showed 2 peaks at $84.5^{\circ} \mathrm{C}$ and $85.6^{\circ} \mathrm{C}$, whereas the wt samples showed only 1 peak at $85.7^{\circ} \mathrm{C}$. Compared to the wt allele, R882X allele was slightly shifted to the left, with a melting temperature of $85.6^{\circ} \mathrm{C}$ (Figure 3.2).
Sensitivity of the HRM assay was assessed similar to that of restriction analysis. The assay had high confidence (97\%99\%) for the mutated allele up to a mutation ratio of 5.9\% (Figure 2.2). Lower mutation ratios could not be assigned as positive and were identified as false negative with a confidence of $92 \%-98 \%$. Thus our results indicated that HRM analysis had a lower sensitivity than that of endonuclease restriction analysis but had the benefit of identifying different mutations in 1 PCR reaction.

\section{IDH2 mutation analysis}

The mutational frequency of IDH2 R140Q G>A was 6.69\% (16 out of 230 patients with AML), which was similar to the frequency published by Paschka et al. [23] and other studies $[29,30]$. Most patients with AML with $I D H 2$ mutations were older than 50 years and had de novo AML and a normal karyotype. Of 16 patients, 7 had an NPM1 mutation.

The ARMS analysis allowed differentiation between mutated and wt DNA of $I D H 2$ through specific differences in the amplification properties of the reaction. In the
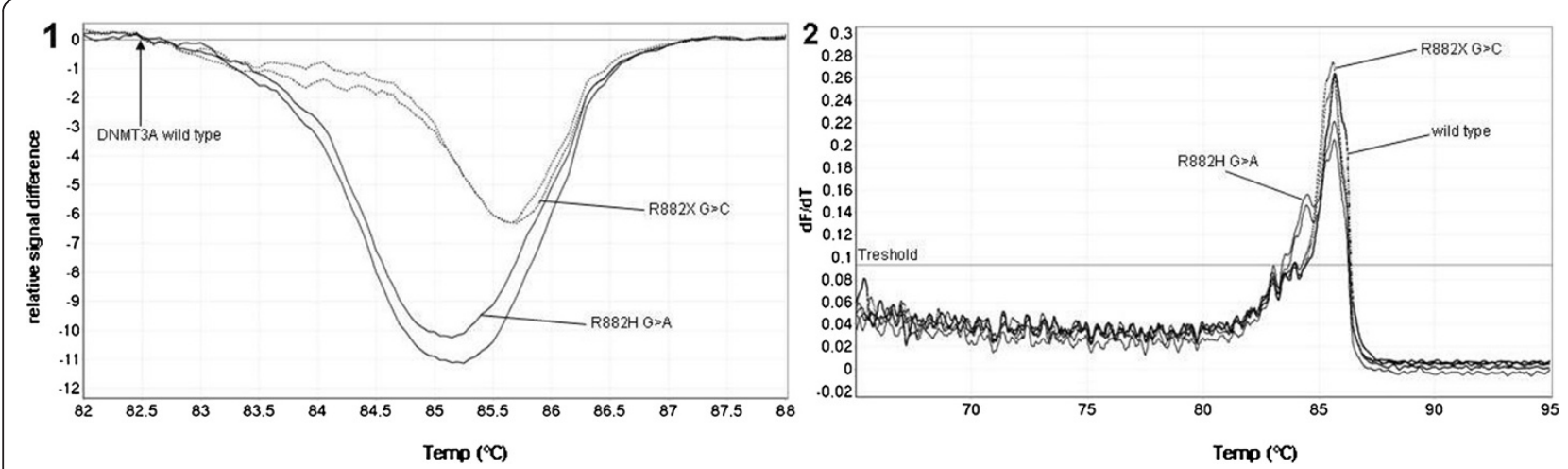

Figure 3 HRM analysis of DNMT3A mutations. 1) Difference plot for HRM analysis of DNMT3A R882H G>A and R882X G>C mutations. Normalisation was performed to the wt allele. R882X showed a right-shifted peak compared to R882H. 2) Melting curve profiles of DNMT3A R882H G>A, R882X G>C and wt allele. Vertical axis corresponds to changes in the fluorescence signal over time $(\mathrm{dF} / \mathrm{dT})$. R882H G>A displayed 2 peaks $\left(84.5^{\circ} \mathrm{C}\right.$ and $\left.85.6^{\circ} \mathrm{C}\right)$, while the wt allele had only one peak at $85.7^{\circ} \mathrm{C}$. R882X G>C had a left shifted peak at $85.6^{\circ} \mathrm{C}$. 

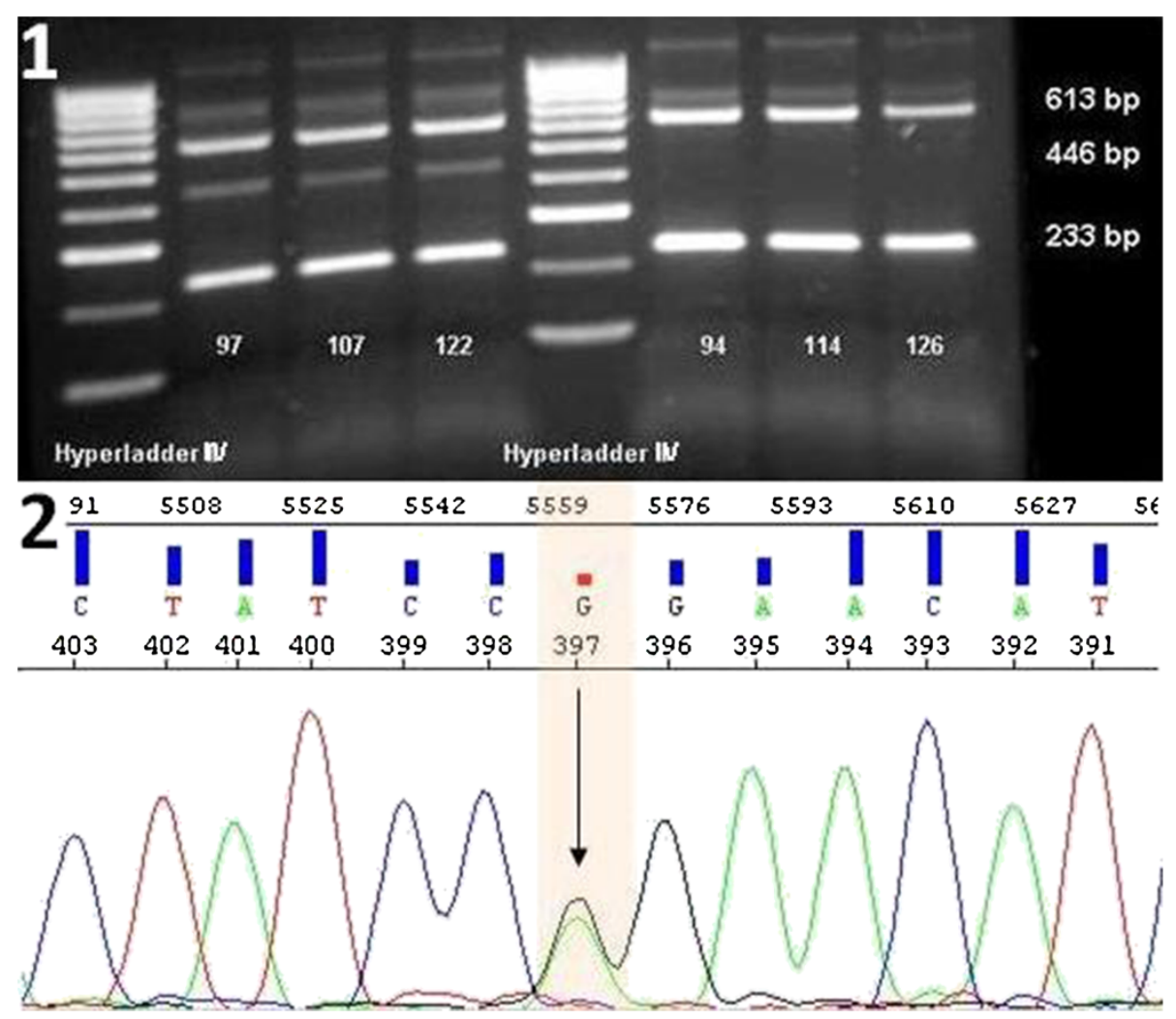

Figure 4 ARMS analysis of IDH2 R140Q mutation. 1) Agarose gel analysis of PCR products of 3 positive $(97,107,122)$ and 3 negative $(94,114,126)$ patients. All patients showed control (613 bp) and wt (233 bp) bands, while only the positive patients showed a product at 446 bp. Hyperladder II (Bioline) was used as the marker. 2) Representative sequence analysis of patient 97 showing the heterozygote mutation CGG to CAG.

presence of a mutation the PCR reaction generated 3 different fragments with sizes $613 \mathrm{bp}$ (control band), 446 (mutation band) and 233 bp (wt band, Figure 4.1). No 446 bp mutation band was detected in the wt samples and results were confirmed by sequencing (Figure 4.2). In addition some faint unspecific bands of size $\geq 613$ bp were detected. Given that the diagnostic approach was not handicapped, the assay was acceptable for further applications. HRM screening of $I D H 2$ showed no additional mutations in our AML patient group. IDH2 amplification

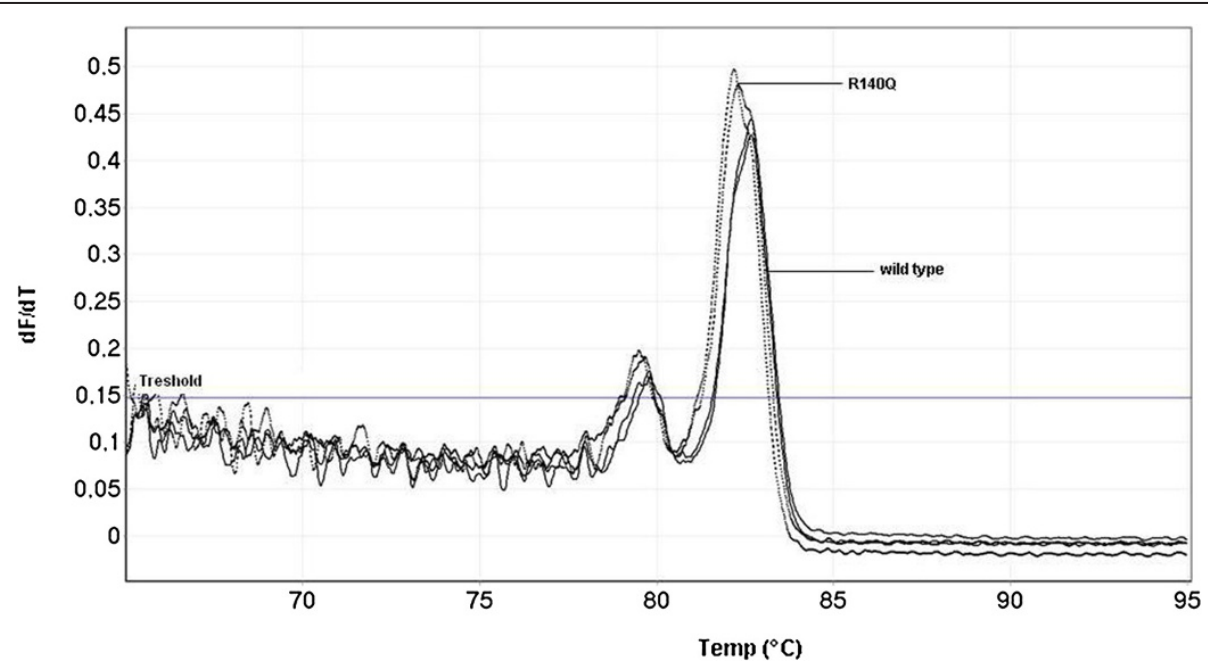

Figure 5 Melting curve profiles of wt allele and IDH2 $140 \mathrm{Q}$ G>A. Vertical axis corresponds to changes in the fluorescence signal over time $(\mathrm{dF} / \mathrm{dT})$. IDH2 analysis showed a bimodal peak; R140Q was shifted to lower temperatures compared to the wt allele. 
showed a bimodal melting profile with a smaller peak at $79.8^{\circ} \mathrm{C}$ and a bigger peak at $82.7^{\circ} \mathrm{C}$. Differences in mutated and wt allele were visible during melting point analysis, because IDH2 R140Q mutations shifted to lower temperatures than those in wt allele (Figure 5). Sensitivity tests were performed as those described for DNMT3A. For the IDH2 allele, the sensitivities of ARMS and HRM analyses were the same, with a limitation at a mutational ratio of 2.25\%. As shown in Figure 6.1 the mutation band at 446 bp was not present in dilutions with $2.25 \%$ and $0.45 \%$ mutated DNA. Furthermore, HRM analysis showed that dilutions from $45 \%$ to $4.5 \%$ were clearly positive with a confidence ranging from $77.68 \%$ to $98.41 \%$, while the last 2 dilutions were false-negative, with a confidence of $82 \%$ to $94.39 \%$ (Figure 6.2).

\section{IDH1 mutation analysis}

An assay to detect specific mutations is not applicable because of the heterogeneity of IDH1 aberrations. Therefore, the HRM assay was evaluated for IDH1, as previously described by Patel et al. [30]. Mutated and wt IDH1 was distinguished through their melting profiles because mutated DNA had a melting point between $80.3^{\circ} \mathrm{C}$ and $80.5^{\circ} \mathrm{C}$ while wt $I D H 1$ had a melting point of $81^{\circ} \mathrm{C}$ (Figure 7.1). However, the distinction between the different mutations of IDH1 was difficult with this analysis as well as with the differentiation plot normalised to the wt control (Figure 7.2). During this study we observed that the temperature-shifted difference plot normalised to R132S C $>$ A control sample was the best to determine different IDH1 mutations (Figure 7.3). Thus, we performed sensitivity tests for G105 $\mathrm{C}>\mathrm{T}$ and $\mathrm{R} 132 \mathrm{C} \mathrm{C}>\mathrm{T}$ with normalisation to $\mathrm{R} 132 \mathrm{~S} \mathrm{C}>\mathrm{A}$ and for R132S C>A with normalisation to G105 C>T (Figure 8). HRM analysis showed sensitivity of $6 \%-7.8 \%$ for all three mutations. Using this method, we determined that 36 out of 230 (15.65\%) patients with AML had IDH1 mutations. Of these 19 (8.3\%) had G105 C>T, 11 (4.8\%) had $\mathrm{R} 132 \mathrm{C} \mathrm{C}>\mathrm{T}$ and $6(2.6 \%)$ had $\mathrm{R} 132 \mathrm{~S} \mathrm{C}>\mathrm{A}$; this frequency is consistent with the data published by Nomdedéu et al. [22,29].

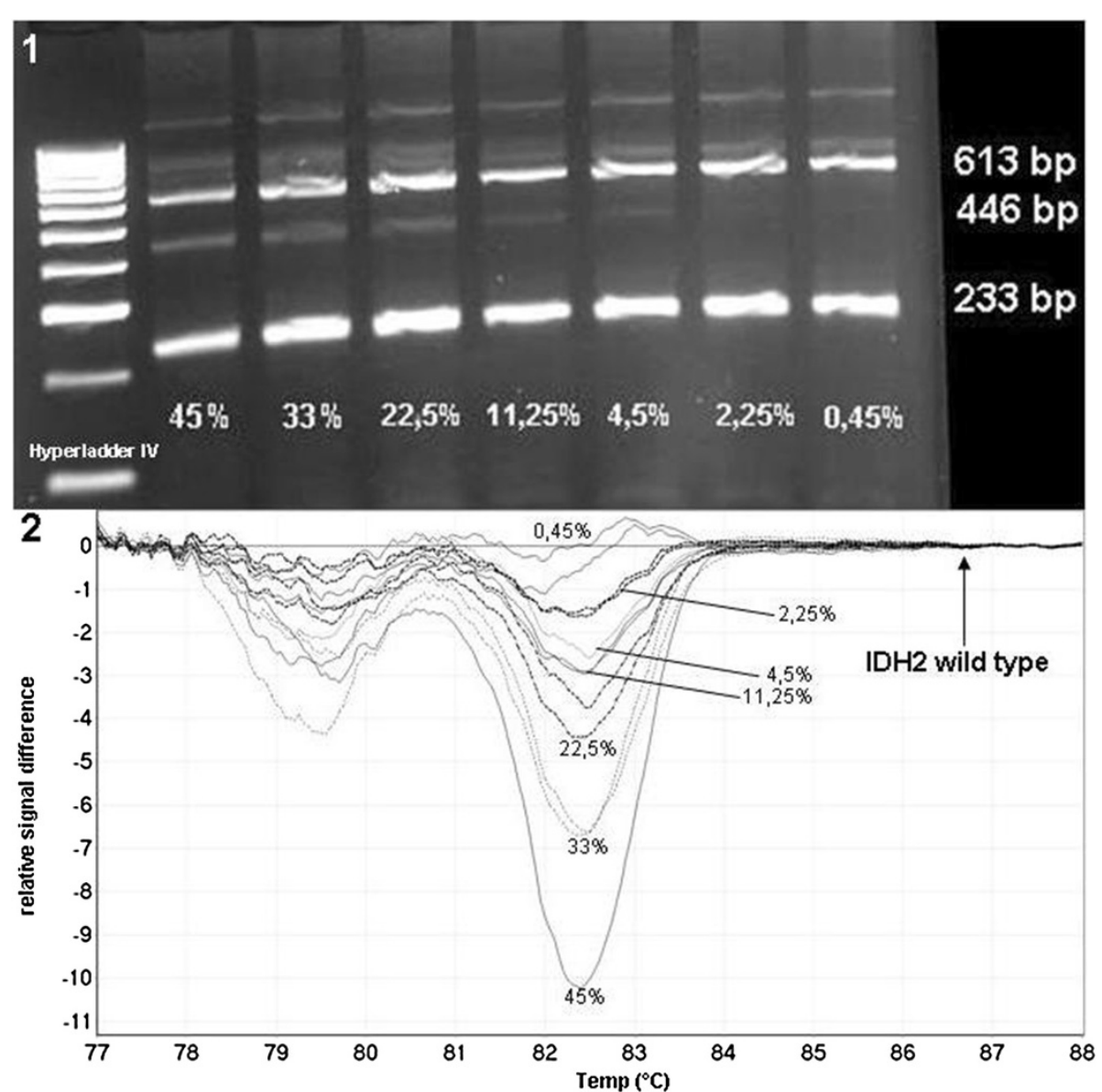

Figure 6 Sensitivity analysis of IDH2 R140Q detection. 1) Serial dilutions of IDH2 R140Q: Undiluted mutation ratio was 45\% (estimated by sequencing). Mutated allele was detected up to a degree of 4.5\%. 2) Difference plot for HRM analysis of serial dilutions of IDH2 R140Q: Correct estimation was possible up to a mutation ratio of $4.5 \%$; lower mutation ratios were identified false-negative. Normalisation was performed to the wt allele. 

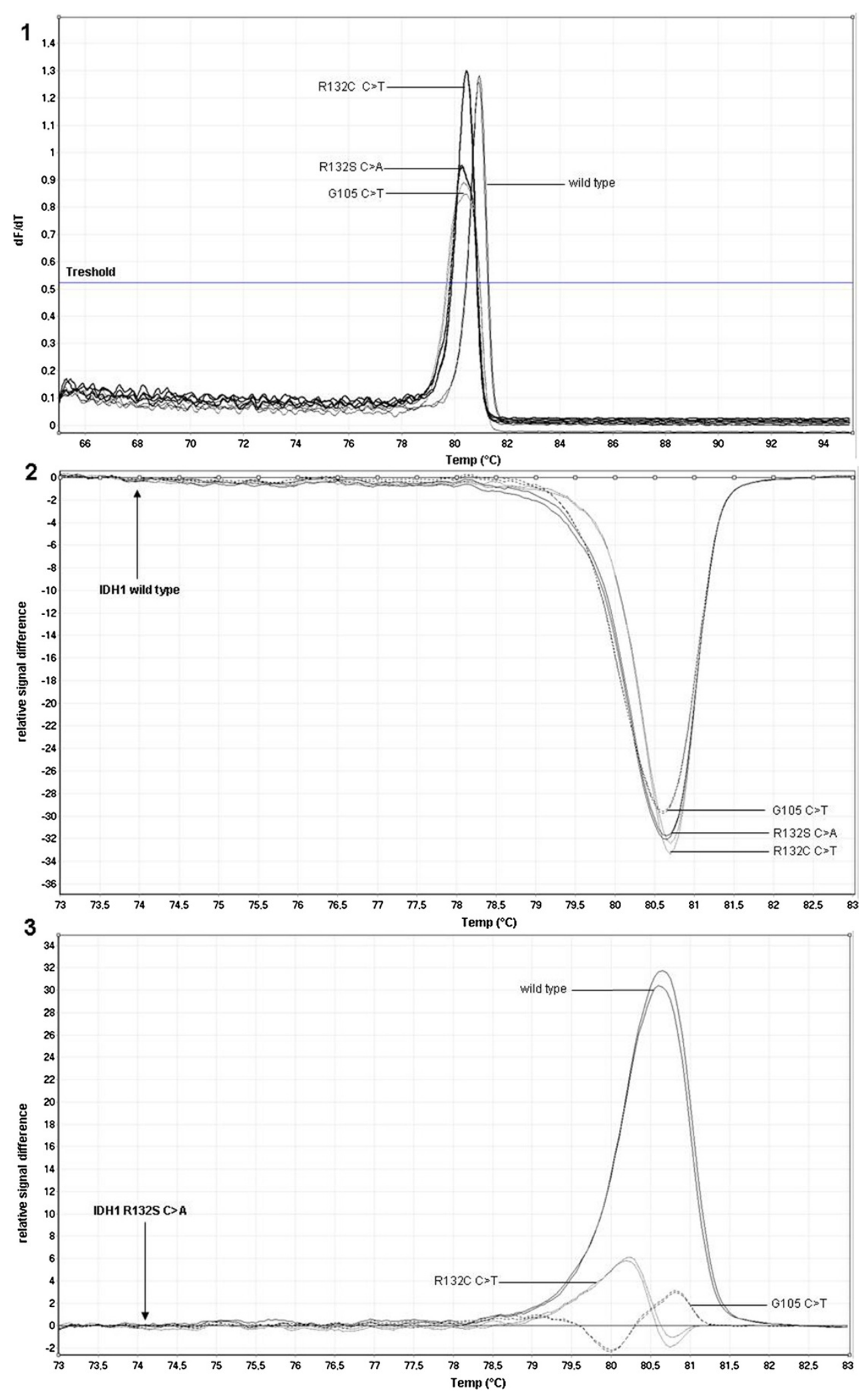

Figure 7 (See legend on next page.) 
Figure 7 HRM analysis of IDH1 mutations. 1) Melting curve profiles of IDHI mutated and wt alleles. Vertical axis corresponds to changes in the fluorescence signal over time (dF/dT). Mutated alleles were shifted to lower temperatures, but differentiation between different mutations was not possible. 2) Difference plot for HRM analysis of $\mathrm{IDH} 1$ mutations normalised to wt allele, discrimination of different mutations was difficult because of similar graphs. 3) Difference plot for HRM analysis of IDH1 mutations normalised to the R132S C>A allele, determination of different mutations was easier because of clearly separated graphs.

\section{Combination of different methods is essential to identify $D N M T 3 A$ and $I D H 1 / 2$ mutations in routine laboratory analyses}

Both the assays designed in this study for the detection of DNMT3A R882H and IDH2 R140Q mutations were completely compliant with Sanger sequencing and had a high specificity. No false-positive results were determined with HRM analysis. Two (0.9\%) samples showed variations for DNMT3A but were subsequently determined as wt by endonuclease restriction and sequencing. IDH1 analysis with HRM showed that $6(2.6 \%)$ samples had inaccuracies in melting profiles and hence were determined false negative with this method. Sequencing showed the presence of a $\mathrm{R} 132 \mathrm{C} \mathrm{C}>\mathrm{T}$ mutation in this samples. IDH2 analysis showed no discrepancies with Sanger sequencing.

Compared to Sanger sequencing, HRM analysis represents a timesaving, cost-efficient and more sensitive method to screen mutations in patients with AML at diagnosis. However, an efficient application presumes the presence of specific mutations and wt control samples. Because of the lack of cell lines with DNMT3A, IDH2 and IDH1 mutations, controls have to be established by sequencing different patient samples. Therefore, an effective application of HRM depends on the identification of high amounts of good-quality control samples, availability of a sequencer and HRM competent real-time PCR cycler. In addition, some results obtained with HRM analysis are difficult to interpret because of the variations in the melting curve of 1 mutation and can lead to uncertain conclusions or false-negative results [31]. Because new studies indicate the prognostic significance of $I D H 1 / 2$ and DNMT3A mutations, which affect the choice of therapy, a steady laboratory diagnosis is essential [10,17,18,21,22,32]. We developed ARMS-PCR to identify IDH2 R140Q mutation and endonuclease restriction analysis to identify DNMT3A $\mathrm{R} 882 \mathrm{H}$ mutations; both these methods are rapid and easy to use and interpret. Thus, these methods can be used to verify unclear results obtained using HRM analysis. In addition, these methods provide a possibility to identify the most common mutations in DNMT3A and IDH2 in laboratories that do not have HRM-competent real-time PCR cyclers at their disposal. Secondary endonuclease restriction has higher sensitivity than HRM analysis that allows earlier identification of mutations at relapse during follow-up analysis [33]. For future applications this assay could also be adapted to the quantitative PCR (qPCR) technique. The forward primer can be modified to amplify only the genomic region containing the restriction position that is lost in the mutated state, thus allowing the exclusion of wt and mutated alleles as well as the quantitative assessment of DNMT3A mutation. The main characteristics of all the methods analysed in this study are summarised in Table 1.

The measured sensitivities depend on assay conditions and equipment. For example, small amounts of nonspecific amplicons and different salt or inhibitory concentrations can influence assay sensitivity [34,35]. Therefore, each laboratory should validate the presented methods with their equipment before application. Both HRM analysis and ARMS-PCR had only low sensitivity, which possibly could lead to false-negative results. Therefore, low mutational ratios could be overlooked and these patients would receive an imprecise laboratory diagnostic report. Potential reduction of amplicon size for both HRM and ARMS analyses could optimise sensitivities [36]. Moreover, adaption of the qualitative endonuclease restriction assay to a quantitative assay could further increase sensitivity and provide objective measurements of mutated cells [37].

In the future, sensitivity limitations for screening DNMT3A and IDH1/2 mutations can be overcome by using allele-specific next-generation sequencing (NGS). This method provides high multiplexing possibilities together with high sensitivity and broad spectrum of detected mutations [38]. However NGS is associated with high costs, high hands-on time and high computational expertise. Because standardisation and validation of NGS can be challenging establishment of this method is an ongoing process in laboratory routine [39]. Conventional PCR-based methods are easy to standardise and validate and therefore could be used when NGS is being implemented in order to provide routine mutational screening of patients with AML.

\section{Possible laboratory workflow for identifying DNMT3A and IDH1/2 mutations}

Although Sanger sequencing is considered as the "gold standard" for identifying mutations, this method is timeconsuming and cost-intensive in routine laboratory practice, because the diagnostic findings need to be available as fast as possible. Based on the findings of this study, we developed a laboratory workflow for identifying $I D H 1 / 2$ and DNMT3A mutations in the first diagnosis and relapse without using of sequencing (Figure 9). HRM analysis should be the method of choice for differentiating between wt and all 

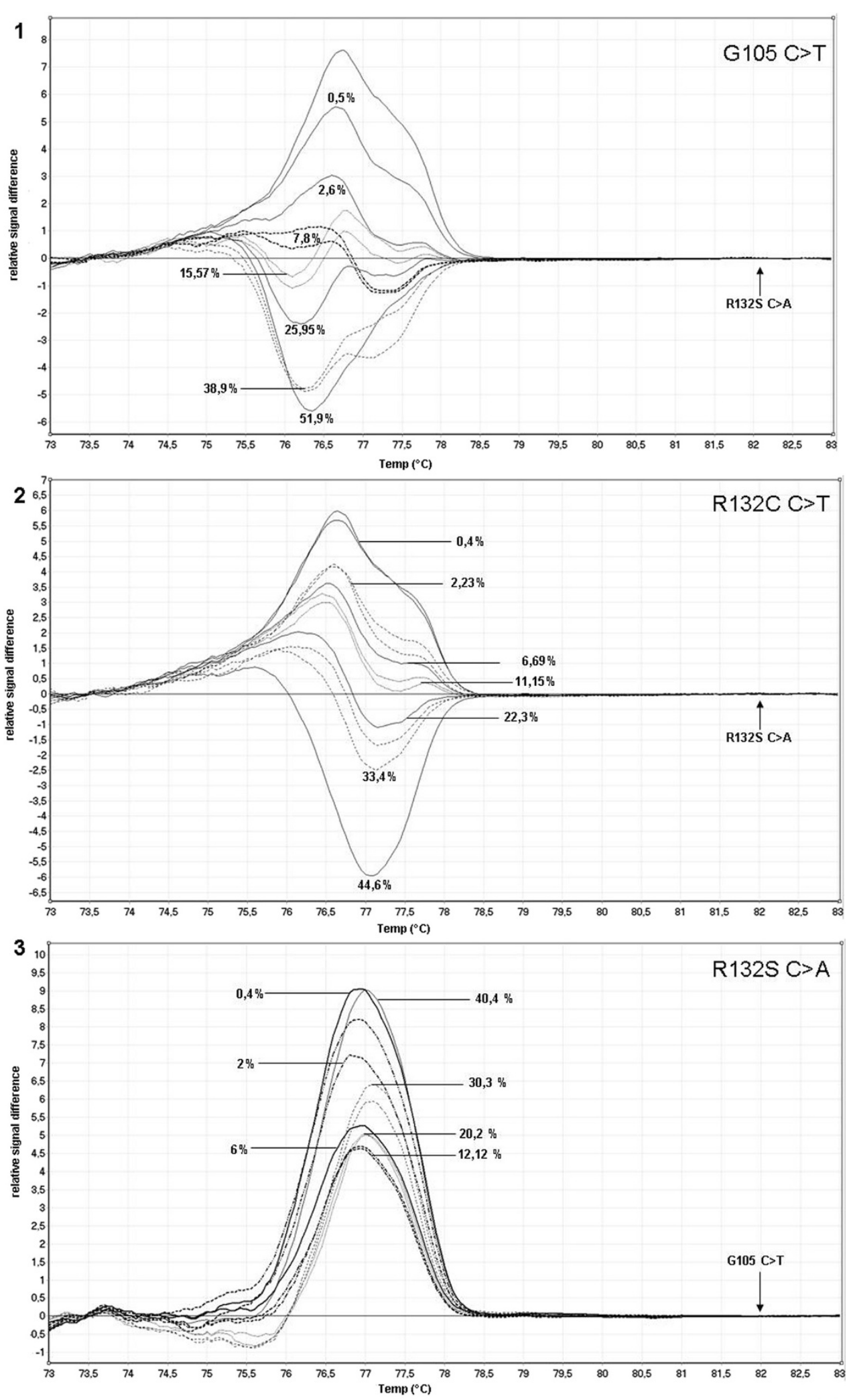

Figure 8 (See legend on next page.) 
(See figure on previous page.)

Figure 8 Sensitivity analysis of different IDH1 mutations. 1) Difference plot for HRM analysis of serial dilutions of IDH1 G105 C>T: Undiluted mutation ratio was $51.9 \%$ (estimated by sequencing). Correct estimation was possible up to a mutation ratio of 7.8\%; lower mutation ratios were identified false-negative. Normalisation was performed to the R132S C>A allele. 2) Difference plot for HRM analysis of serial dilutions of IDH1 R132C C>T: Undiluted mutation ratio was 44.6\% (estimated by sequencing). Correct estimation was possible up to a mutation ratio of $6.69 \%$; lower mutation ratios were identified false-negative. Normalisation was performed to the R132S C>A allele. 3) Difference plot for HRM analysis of serial dilutions of IDH1 R132S C>A: Undiluted mutation ratio was 40.4\% (estimated by sequencing). Correct estimation was possible up to a mutation ratio of $6 \%$, lower mutation ratios were identified false-negative. Normalisation was performed to the G105 C>T allele.

Table 1 Comparative characteristics of all the methods used in this study

\begin{tabular}{|c|c|c|c|c|c|c|c|c|}
\hline & \multicolumn{3}{|c|}{ DNMT3A } & \multicolumn{3}{|c|}{ IDH2 } & \multicolumn{2}{|l|}{ IDH1 } \\
\hline & $\begin{array}{l}\text { Restriction } \\
\text { endonuclease }\end{array}$ & HRM & $\begin{array}{c}\text { Sanger } \\
\text { sequencing }\end{array}$ & ARMS & HRM & $\begin{array}{c}\text { Sanger } \\
\text { sequencing }\end{array}$ & HRM & $\begin{array}{c}\text { Sanger } \\
\text { sequencing }\end{array}$ \\
\hline Sensitivity ${ }^{*}, \%$ & 0.05 & 5.9 & 10 & 4.5 & 4.5 & 10 & 6 to 7.8 & 10 \\
\hline Turnaround time, days & 1 & 1 & 2 to 3 & 1 & 1 & 2 to 3 & 1 & 2 to 3 \\
\hline Technician time, hours & 4 & 3.5 & 10 to 12 & 3 & 3.5 & 10 to 12 & 3.5 & 10 to 12 \\
\hline $\begin{array}{l}\text { Cost of diagnosis } \\
\text { method, } €\end{array}$ & 32.13 & 28 & 122 & 44.16 & 28 & 122 & 28 & 122 \\
\hline Interpretation & Easy & Medium -difficult & Medium & Easy & Medium -difficult & Medium & Medium -difficult & Medium \\
\hline $\begin{array}{l}\text { Identification of } \\
\text { different/rare mutations }\end{array}$ & No & Yes & Yes & No & Yes & Yes & Yes & Yes \\
\hline Special equipment & PCR cycler & $\begin{array}{c}\text { HRM real } \\
\text { time PCR cycler }\end{array}$ & Sequencer & PCR cycler & $\begin{array}{l}\text { HRM real time } \\
\text { real time PCR cycler }\end{array}$ & Sequencer & $\begin{array}{l}\text { HRM real time } \\
\text { real time PCR cycler }\end{array}$ & Sequencer \\
\hline
\end{tabular}

*Sensitivity was measured as the minimal percentage of mutated allele in a sample detected by the assay.

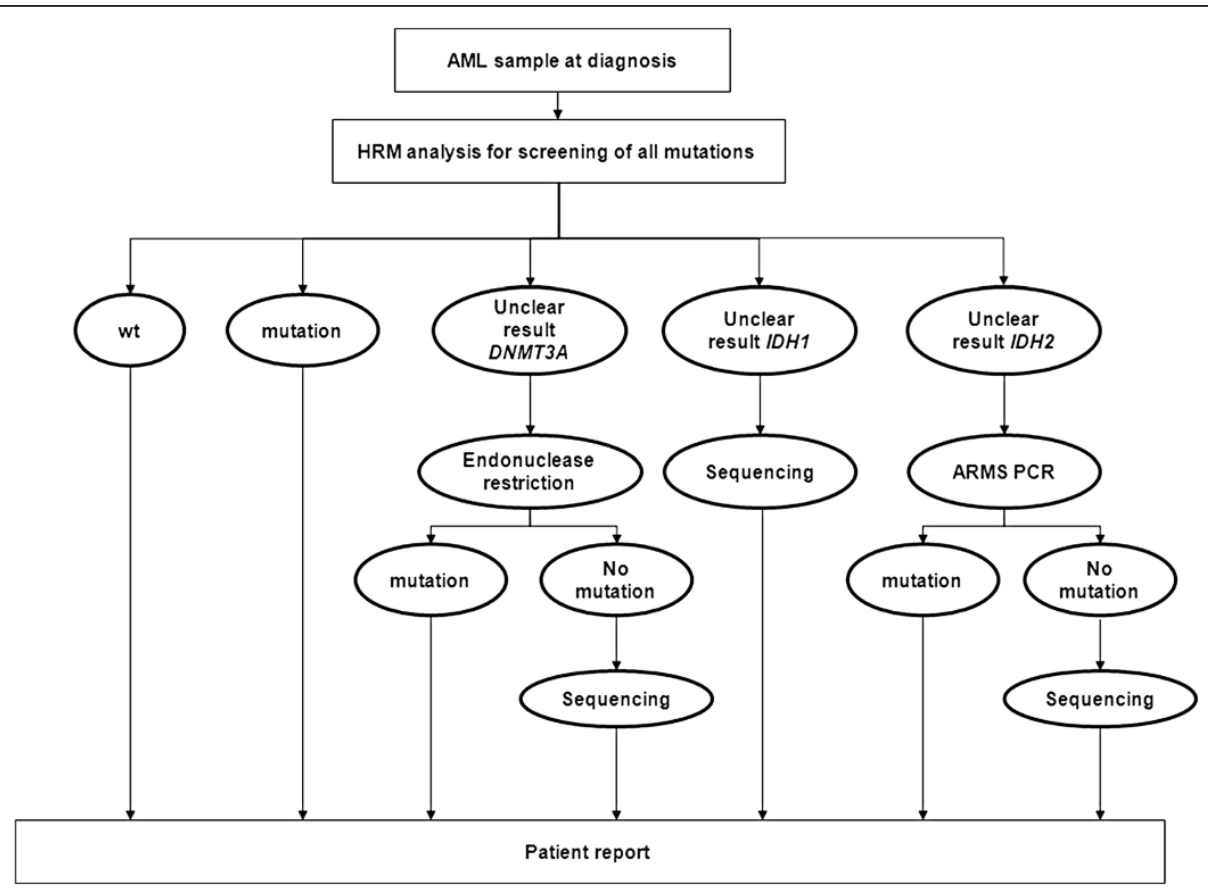

Figure 9 Possible diagnostic workflow to identify DNMT3A, IDH2 and IDH1 mutations in routine laboratory analysis. HRM analysis can be performed in the first diagnosis for all mutations because of high mutational ratios prior to therapy. Unclear results can be verified by endonuclease restriction or ARMS-PCR. Unclear IDH1 results can be checked by sequencing because of the heterogeneity of possible mutations. Effective combination of all the available methods enables more reliable results and a cost-effective and time-saving routine laboratory analysis. 
the analysed mutations in primary AML samples. In case of uncertainty results can be verified using the above presented methods. In addition, ARMS and endonuclease restriction provide a possibility to identify the most common $I D H 2$ and DNMT3A mutations when no HRM-compatible real-time PCR cycler is available. Because of the multiplicity of $I D H 1$ mutations, it was not possible to generate a valid method for analysing 1 specific mutation. For this reason HRM analysis is the best alternative to Sanger sequencing. After therapy, follow-up analysis should be chosen depending on the identified mutations at the first diagnosis. Because endonuclease restriction had higher sensitivity for $\mathrm{R} 882 \mathrm{H}$ mutations, this method is more suitable for detecting low mutational ratio of known mutations in patients after therapy or relapse and progression of disease. Because of the ease of interpretation ARMS can also be used to identify $I D H 2$ R140Q mutations at relapse or disease progression.

\section{Conclusion}

In summary, we generated highly specific, sensitive and rapid methods for identifying the most common mutations in IDH2 (R140Q) and DNMT3A (R882H), which can be used separately or in combination with HRM analysis to provide more reliable diagnostic results. All the developed methods were rapid, specific and easy to use and interpret. PCR-based methods are a useful tool for the routine laboratory identification of relevant prognostic mutations. We propose that early screening of mutations in patients with AML with normal karyotype could facilitate risk stratification and improve treatment opportunities.

\section{Additional files}

Additional file 1: Table S1. Characteristics of patients with AML according to mutation status.

Additional file 2: Table S2. Primers used in this study.

Additional file 3: PCR reaction mixtures and conditions.

\section{Abbreviations}

AML: Acute myeloid leukemia; IDH: Isocitrate dehydrogenase; DNMT: DNA methyltransferase; HRM: High resolution melt; PCR: Polymerase chain reaction; a-KG: a-ketoglutarate; 2-HG: 2-hydroxyglutarate; NADP: Nicotinamide adenine dinucleotide phosphate; ARMS: Amplification-refractory mutation system; NPM: Nucleophosmin; FLT: fms-related tyrosine kinase.

\section{Competing interests}

The authors declare that they have no competing interest.

\section{Authors' contributions}

BR carried out design of the study and drafted the manuscript. BO and BIW conceived of the study, and participated in its design and coordination and helped to draft the manuscript. KA and CR carried out the molecular genetic studies. SA and SC participated in sample collection and sequencing. All authors read and approved the final manuscript.

\section{Acknowledgment}

This work was supported by the Stefan-Morsch-Stiftung for Leukemia Tumour Patients.

\section{Author details}

'Department of Hematology, Oncology and Tumourimmunology, Charité Universitätsmedizin Berlin, Hindenburgdamm 30, 12200 Berlin, Germany. ${ }^{2}$ Department of Biotechnology, Beuth University of Applied Sciences,

Luxemburger Strasse 10, 13353 Berlin, Germany. ${ }^{3}$ Labor Berlin, Department of Hematology and Oncology, Charité Universitätsmedizin Berlin, Sylterstrasse 2, 13353 Berlin, Germany.

Received: 19 February 2014 Accepted: 10 May 2014

Published: 21 May 2014

\section{References}

1. Estey EH: Acute myeloid leukemia: 2013 update on risk-stratification and management. Am J Hematol 2013, 88(4):318-327.

2. Cancer Genome Atlas Research, N: Genomic and epigenomic landscapes of adult de novo acute myeloid leukemia. N Engl J Med 2013, 368(22):2059-2074.

3. Im AP, Sehgal AR, Carroll MP, Smith BD, Tefferi A, Johnson DE, Boyiadzis M: DNMT3A and IDH mutations in acute myeloid leukemia and other myeloid malignancies: associations with prognosis and potential treatment strategies. Leukemia 2014. Epub ahead of print, doi:10.1038/leu.2014.124.

4. Li KK, Luo LF, Shen Y, XU J, Chen Z, Chen SJ: DNA methyltransferases in hematologic malignancies. Semin Hematol 2013, 50(1):48-60.

5. Ley TJ, Ding L, Walter MJ, McLellan MD, Lamprecht T, Larson DE, Kandoth C, Payton JE, Baty J, Welch J, Harris CC, Lichti CF, Townsend RR, Fulton RS, Dooling DJ, Koboldt DC, Schmidt H, Zhang Q, Osborne JR, Lin L, O'Laughlin M, McMichael JF, Delehaunty KD, McGrath SD, Fulton LA, Magrini VJ, Vickery TL, Hundal J, Cook LL, Conyers JJ, et al: DNMT3A mutations in acute myeloid leukemia. N Engl J Med 2010, 363(25):2424-2433.

6. Marcucci G, Metzeler KH, Schwind S, Becker H, Maharry K, Mrozek K, Radmacher MD, Kohlschmidt J, Nicolet D, Whitman SP, Wu YZ, Powell BL, Carter TH, Kolitz JE, Wetzler M, Carroll AJ, Baer MR, Moore JO, Caligiuri MA, Larson RA, Bloomfield CD: Age-related prognostic impact of different types of DNMT3A mutations in adults with primary cytogenetically normal acute myeloid leukemia. J Clin Oncol 2012, 30(7):742-750.

7. Yamashita Y, Yuan J, Suetake I, Suzuki H, Ishikawa Y, Choi YL, Ueno T, Soda M, Hamada T, Haruta H, Takada S, Miyazaki Y, Kiyoi H, Ito E, Naoe T, Tomonaga M, Toyota M, Tajima S, Iwama A, Mano H: Array-based genomic resequencing of human leukemia. Oncogene 2010, 29(25):3723-3731.

8. Shih AH, Abdel-Wahab O, Patel JP, Levine RL: The role of mutations in epigenetic regulators in myeloid malignancies. Nat Rev Cancer 2012, 12(9):599-612.

9. Dinardo CD, Patel KP, Garcia-Manero G, Luthra R, Pierce S, Borthakur G, Jabbour E, Kadia T, Pemmaraju N, Konopleva M, Faderl S, Cortes J, Kantarjian HM, Ravandi F: Lack of association of IDH1, IDH2 and DNMT3A mutations with outcome in older patients with acute myeloid leukemia treated with hypomethylating agents. Leuk Lymphoma 2014, Epub ahead of print.

10. Feng JH, Guo XP, Chen YY, Wang ZJ, Cheng YP, Tang YM: Prognostic significance of $I D H 1$ mutations in acute myeloid leukemia: a metaanalysis. Am J Blood Res 2012, 2(4):254-264.

11. Abdel-Wahab O, Patel J, Levine RL: Clinical implications of novel mutations in epigenetic modifiers in AML. Hematol Oncol Clin North Am 2011, 25(6):1119-1133.

12. Dang L, Jin S, Su SM: IDH mutations in glioma and acute myeloid leukemia. Trends Mol Med 2010, 16(9):387-397.

13. Losman JA, Kaelin WG Jr: What a difference a hydroxyl makes: mutant IDH, (R)-2-hydroxyglutarate, and cancer. Genes Dev 2013, 27(8):836-852.

14. Zhang Y, Chen FQ, Sun YH, Zhou SY, Li TY, Chen R: Effects of DNMT1 silencing on malignant phenotype and methylated gene expression in cervical cancer cells. J Exp Clin Cancer Res 2011, 30:98.

15. Lu Q, Chen Y, Wang H, Li Z: DNMT3A mutations and clinical features in Chinese patients with acute myeloid leukemia. Cancer Cell Int 2013, 13(1):1.

16. Markova J, Michkova P, Burckova K, Brezinova J, Michalova K, Dohnalova A, Maaloufova JS, Soukup P, Vitek A, Cetkovsky P, Schwarz J: Prognostic impact of DNMT3A mutations in patients with intermediate cytogenetic risk profile acute myeloid leukemia. Eur J Haematol 2012, 88(2):128-135.

17. Ribeiro AF, Pratcorona M, Erpelinck-Verschueren C, Rockova V, Sanders M, Abbas S, Figueroa ME, Zeilemaker A, Melnick A, Lowenberg B, Valk PJ, 
Delwel R: Mutant DNMT3A: a marker of poor prognosis in acute myeloid leukemia. Blood 2012, 119(24):5824-5831.

18. Schwarz J, Markova J: DNMT3A mutations in AML: a new prognostic factor? Leuk Res 2013, 37(11):1432-1433.

19. Thol F, Damm F, Ludeking A, Winschel C, Wagner K, Morgan M, Yun $H_{\text {, }}$ Gohring G, Schlegelberger B, Hoelzer D, Lubbert M, Kanz L, Fiedler W, Kirchner H, Heil G, Krauter J, Ganser A, Heuser M: Incidence and prognostic influence of DNMT3A mutations in acute myeloid leukemia. J Clin Oncol 2011, 29(21):2889-2896.

20. Wang Z, Bao Z, Yan W, You G, Wang Y, Li X, Zhang W: Isocitrate dehydrogenase 1 (IDH1) mutation-specific microRNA signature predicts favorable prognosis in glioblastoma patients with $I D H 1$ wild type. J Exp Clin Cancer Res 2013, 32(1):59.

21. Koszarska M, Bors A, Feczko A, Meggyesi N, Batai A, Csomor J, Adam E, Kozma A, Orban TI, Lovas N, Sipos A, Karaszi E, Dolgos J, Fekete S, Reichardt J, Lehoczky E, Masszi T, Tordai A, Andrikovics H: Type and location of isocitrate dehydrogenase mutations influence clinical characteristics and disease outcome of acute myeloid leukemia. Leuk Lymphoma 2013, 54(5):1028-1035.

22. Nomdedeu J, Hoyos M, Carricondo M, Esteve J, Bussaglia E, Estivill C, Ribera JM, Duarte R, Salamero O, Gallardo D, Pedro C, Aventin A, Brunet S, Sierra J: Adverse impact of IDH1 and IDH2 mutations in primary AML: experience of the Spanish CETLAM group. Leuk Res 2012, 36(8):990-997.

23. Paschka P, Schlenk RF, Gaidzik VI, Habdank M, Kronke J, Bullinger L, Spath D, Kayser S, Zucknick M, Gotze K, Horst HA, Germing U, Dohner H, Dohner K: $I D H 1$ and IDH2 mutations are frequent genetic alterations in acute myeloid leukemia and confer adverse prognosis in cytogenetically normal acute myeloid leukemia with NPM1 mutation without FLT3 internal tandem duplication. J Clin Oncol 2010, 28(22):3636-3643.

24. Julie Schanz M, Friederike Braulke P, Katayoon Shirneshan M, Kathrin Nachtkamp M, Ulrich Germing M, Stephan Schmitz M, Peter Haas M, Michael Lübbert M, Müller-Thomas C, Katharina G, Uwe Platzbecker M, Florian Nolte M, Wolf-Karsten Hofmann M, Detlef Haase M: Therapy with demethylating agents significantly improves overall- and AML-free survival in patients with MDS classified as high-risk by IPSS or very high risk by IPSS-R and partial or total monosomy 7-results from a German Multicenter Study. Blood 2013, 122(21):2784.

25. Mani S, Herceg Z: DNA demethylating agents and epigenetic therapy of cancer. Adv Genet 2010, 70:327-340.

26. Vardiman JW, Thiele J, Arber DA, Brunning RD, Borovitz MJ, Porwit A, Harris NL, Le Beau MM, Hellström-Lindberg E, Tefferi A, Bloomfield CD: The 2008 revision of the World Health Organization (WHO) classification of the myeloid neoplasms and leukemia: rationale and important changes. Blood 2009, 114(5):937-951.

27. Jaatinen T, Laine J: Isolation of mononuclear cells from human cord blood by Ficoll-Paque density gradient. Curr Protoc Stem Cell Biol 2007, Chapter 2:Unit 2A.1.

28. Lin J, Yao DM, Qian J, Chen Q, Qian W, Li Y, Yang J, Wang CZ, Chai HY, Qian Z, Xiao GF, Xu WR: Recurrent DNMT3A R882 mutations in Chinese patients with acute myeloid leukemia and myelodysplastic syndrome. PLoS One 2011, 6(10):e26906.

29. Chotirat S, Thongnoppakhun W, Promsuwicha O, Boonthimat C, Auewarakul CU: Molecular alterations of isocitrate dehydrogenase 1 and 2 (IDH1 and IDH2) metabolic genes and additional genetic mutations in newly diagnosed acute myeloid leukemia patients. J Hematol Oncol 2012, 5:5

30. Patel KP, Barkoh BA, Chen Z, Ma D, Reddy N, Medeiros $\sqcup$, Luthra R: Diagnostic testing for $I D H 1$ and $I D H 2$ variants in acute myeloid leukemia an algorithmic approach using high-resolution melting curve analysis. J Mol Diagn 2011, 13(6):678-686.

31. Jancik S, Drabek J, Berkovcova J, Xu YZ, Stankova M, Klein J, Kolek V, Skarda J, Tichy T, Grygarkova I, Radzioch D, Hajduch M: A comparison of Direct sequencing, Pyrosequencing, High resolution melting analysis, TheraScreen DxS, and the K-ras StripAssay for detecting KRAS mutations in non small cell lung carcinomas. J Exp Clin Cancer Res 2012, 31:79.

32. Shivarov V, Gueorguieva R, Stoimenov A, Tiu R: DNMT3A mutation is a poor prognosis biomarker in AML: results of a meta-analysis of 4500 AML patients. Leuk Res 2013, 37(11):1445-1450.

33. Cikota BM, Tukic LJ, Tarabar OT, Magic ZM: Detection of $\mathrm{t}(14 ; 18), \mathrm{P} 53$ and RAS gene mutations and quantification of residual disease in patients with B-cell non-Hodgkin's lymphoma. J Exp Clin Cancer Res 2007, 26(4):535-542
34. Pichler M, Balic M, Stadelmeyer E, Ausch C, Wild M, Guelly C, Bauernhofer T, Samonigg H, Hoefler G, Dandachi N: Evaluation of high-resolution melting analysis as a diagnostic tool to detect the BRAF V600E mutation in colorectal tumors. J Mol Diagn 2009, 11(2):140-147.

35. Krypuy M, Newnham GM, Thomas DM, Conron M, Dobrovic A: High resolution melting analysis for the rapid and sensitive detection of mutations in clinical samples: KRAS codon 12 and 13 mutations in non-small cell lung cancer. BMC Cancer 2006, 6:295.

36. Ellison G, Donald E, McWalter G, Knight L, Fletcher L, Sherwood J, Cantarini M, Orr M, Speake G: A comparison of ARMS and DNA sequencing for mutation analysis in clinical biopsy samples. J Exp Clin Cancer Res 2010, 29:132.

37. Oakes CC, La Salle S, Trasler JM, Robaire B: Restriction digestion and real-time PCR (qAMP). Methods Mol Biol 2009, 507:271-280.

38. Altimari A, de Biase D, De Maglio G, Gruppioni E, Capizzi E, Degiovanni A, D'Errico A, Pession A, Pizzolitto S, Fiorentino M, Tallini G: 454 next generationsequencing outperforms allele-specific PCR, Sanger sequencing, and pyrosequencing for routine KRAS mutation analysis of formalin-fixed, paraffin-embedded samples. Onco Targets Ther 2013, 6:1057-1064.

39. Ihle MA, Fassunke J, Konig K, Grunewald I, Schlaak M, Kreuzberg N, Tietze L, Schildhaus HU, Buttner R, Merkelbach-Bruse S: Comparison of high resolution melting analysis, pyrosequencing, next generation sequencing and immunohistochemistry to conventional Sanger sequencing for the detection of p.V600E and non-p.V600E BRAF mutations. BMC Cancer 2014, 14:13.

doi:10.1186/1756-9966-33-44

Cite this article as: Berenstein et al:: Comparative examination of various PCR-based methods for DNMT3A and IDH1/2 mutations identification in acute myeloid leukemia. Journal of Experimental \& Clinical Cancer Research 2014 33:44

\section{Submit your next manuscript to BioMed Central and take full advantage of:}

- Convenient online submission

- Thorough peer review

- No space constraints or color figure charges

- Immediate publication on acceptance

- Inclusion in PubMed, CAS, Scopus and Google Scholar

- Research which is freely available for redistribution

Submit your manuscript at www.biomedcentral.com/submit
C Biomed Central 